\title{
Comparison of the Clinical Efficacies of Fentanyl, Esmolol and Lidocaine in Preventing the Hemodynamic Responses to Endotracheal Intubation and Extubation
}

\author{
Habib Bostan ${ }^{\mathrm{a}}$, Ahmet Eroglu ${ }^{\mathrm{b}, \mathrm{c}}$
}

\begin{abstract}
Background: We compared the efficacy of intravenous fentanyl, esmolol and lidocaine in preventing hemodynamic response to laryngoscopy, endotracheal intubation and extubation in abdominal surgeries.
\end{abstract}

Methods: A hundred and twenty patients (aging from 18 to 65, ASA class I or II, Mallampati grade I) were randomly divided into 4 groups. Fentanyl $1 \mu \mathrm{g} \mathrm{kg}^{-1}(\mathrm{n}=30)$, Esmolol $1 \mathrm{mg} \mathrm{kg}^{-1}(\mathrm{n}=$ 30), Lidocaine $1 \mathrm{mg} \mathrm{kg}^{-1}(\mathrm{n}=30)$ and $\mathrm{NaCl}$ 0.9\% $10 \mathrm{~mL}$ (Control group, $\mathrm{n}=30$ ) were administered before induction and extubation. Heart rate, systolic arterial pressure and diastolic arterial pressure were recorded before anesthesia induction and at laryngoscopy, at 1st, 3rd ,5th and 10th minutes of intubation, and then at the end of surgery before extubation, and at $1 \mathrm{st}, 3 \mathrm{rd}$, 5th, and 10 th minutes following extubation. Amounts of the administered drugs and side effects were recorded.

Results: The heart rates and the arterial blood pressures values of the study groups after intubation and extubation were lower than those in the control group $(\mathrm{P}<0.01)$. The heart rates, the systolic and diastolic arterial blood pressure values after intubation and ex-

Manuscript accepted for publication February 9, 2012

\footnotetext{
${ }^{a}$ Rize University, Faculty of Medicine, Department of Anesthesiology and Reanimation, Rize, Turkey

${ }^{\mathrm{b}}$ Karadeniz Technical University, Faculty of Medicine, Department of Anesthesiology and Reanimation, Trabzon, Turkey

${ }^{c}$ Corresponding author: Ahmet Eroglu, Karadeniz Technical University, Anaesthesiology, Trabzon, Turkey. Email: erogluah@hotmail.com
}

doi:10.4021/jcs31e tubation at 1 st, 3 th, and 5 th minutes were significantly lower in esmolol group when compared to fentanyl and lidocaine groups ( $\mathrm{P}$ $<0.05)$. In all other measurement times, there was no any different of hemodynamic among the three groups.

Conclusions: When administered before induction and emergency of anesthesia $1 \mathrm{mg} \mathrm{kg}^{-1}$ of esmolol and lidocaine, and $1 \mu \mathrm{g} \mathrm{kg}^{-1}$ of fentanyl are effective in suppressing the hemodynamic response to laryngoscopy, intubation and extubation. Esmolol may be more effective to prevent those responses comparing fentanyl and lidocaine. Furthermore studies regarding the dose of those drugs should be required.

Keywords: Hemodynamic response; Intubation; Extubation; Esmolol; Lidocaine; Fentanyl

\section{Introduction}

Laryngeal, tracheal and bronchial receptors are stimulated by mechanical and chemical irritants during laryngoscopy, intubation and extubation [1]. The reflex increase in sympathoadrenergic activity caused by these manipulations leads to an increase in catecholamine release, arterial blood pressure and heart rate. This response may lead to increased morbidity and life threatening complications in patients with intracranial and cardiovascular problems [2, 3]. Both intravenous and topical local anesthetics, $\alpha$-adrenergic blockers, $\beta$-adrenergic blockers, calcium-channel blockers, vasodilators and opioids have been used to prevent those responses, resulting in different side effects [4-7]. Some of these side effects including increased sedation, difficulty in coughing and swallowing limit their use during extubation. Such complications may cause delayed discharge of the patient from the operating room or postanesthetic care unit.

In this study we aimed to compare the clinical efficacies of fentanyl, lidocaine and esmolol in preventing the hemodynamic responses to laryngoscopy, intubation and extubation. There are previous studies evaluating effects of fentanyl, lidocaine and esmolol to laryngeal stimulation. However since preservation of laryngeal reflexes is important to provide a safe and efficient postanesthesia care for the patient, we also 
Table 1. Patient Demographics $(P>0.05)$

\begin{tabular}{lllll}
\hline & $\begin{array}{l}\text { Fentanyl group } \\
(\mathbf{n}=\mathbf{3 0})\end{array}$ & $\begin{array}{l}\text { Esmolol group } \\
(\mathbf{n}=\mathbf{3 0})\end{array}$ & $\begin{array}{l}\text { Lidocaine group } \\
(\mathbf{n}=\mathbf{3 0})\end{array}$ & $\begin{array}{l}\text { Control group } \\
(\mathbf{n}=\mathbf{3 0})\end{array}$ \\
\hline Age (years) & $38.7 \pm 15.4$ & $39.2 \pm 16.3$ & $40.5 \pm 12,6$ & $39.9 \pm 14.6$ \\
Weight $(\mathrm{kg})$ & $68.8 \pm 9.5$ & $67.6 \pm 11.5$ & $72.1 \pm 10.7$ & $70.7 \pm 11.6$ \\
Height $(\mathrm{cm})$ & $168 \pm 15$ & $165 \pm 12$ & $166 \pm 14$ & $169 \pm 16$ \\
ASA $(1 / 2)$ & $16 / 14$ & $17 / 13$ & $15 / 15$ & $16 / 14$ \\
Sex $(\mathrm{M} / \mathrm{F})$ & $17 / 13$ & $15 / 15$ & $13 / 17$ & 16 \\
\hline
\end{tabular}

evaluated these drugs during periextubation period.

\section{Materials and Methods}

A hundred and twenty patients were enrolled in this prospective clinical study. Ethical committee approval was obtained from the Ethical Committee of Karadeniz Technical University, Faculty of Medicine. All patients gave written informed consent.

Inclusion criteria were: ASA class I or II, age range 18 - 65, oropharyngeal anatomy of Mallampati class I and any operation other than cardiac surgery performed under general anesthesia with endotracheal intubation.

Exclusion criteria were: morbid obesity, cardiac and respiratory disease, a history of allergy to the study drugs, antihypertensive medication, opioids and/or sedative medication use, history of difficult intubation and laryngoscopy time over 30 seconds.

Premedication was none. Electrocardiograms, noninvasive blood pressures and peripheral oxygen saturations of the patients were monitorized. Patients were randomly divided to 4 groups, and the study solution $(10 \mathrm{~mL})$ was blindly administered. The groups were organized as follows:

Fentanyl group (Group F, $\mathrm{n}=30$ ): Intravenous (IV) Fentanyl $1 \mu \mathrm{g} \mathrm{kg}^{-1}$ was administered before intubation and extubation.

Esmolol group (Group $\mathrm{E}, \mathrm{n}=30$ ): Esmolol $1 \mathrm{mg} \mathrm{kg}^{-1} \mathrm{IV}$ was administered before intubation and extubation.

Lidocaine group (Group L, $\mathrm{n}=30$ ): Lidocaine $1 \mathrm{mg} \mathrm{kg}^{-1}$ IV was administered before intubation and extubation.

Control group (Group $\mathrm{C}, \mathrm{n}=30$ ): $10 \mathrm{~mL}$ of isotonic $\mathrm{NaCl}$ IV was administered before intubation and extubation.

The study was done in a double blind fashion. The patients were numbered consecutively from 1 to 120 . Only the leading author knew the drugs in the injectors and to which patient they were administered. The people who applied the drugs or who recorded the data did not know the contents of the injectors. The drugs were given in a dose of $0.1 \mathrm{ml} \mathrm{kg}^{-1}$ in $10 \mathrm{~mL}$ solutions and were applied in 20 seconds using the IV line. After the administration of the study drugs, $5 \mathrm{mg} \mathrm{kg}^{-1}$ tiopenthal and $0.1 \mathrm{mg} \mathrm{kg}^{-1}$ vecuronium were used for anesthesia induction. A gas mixture of $40 \%$ oxygen, $60 \%$ nitrous oxide and 1.5 - $2 \%$ sevoflurane was used for ventilation. Laryngoscopy and intubation were carried out after a response of 0 to Train-of-Four was detected. Anesthesia maintenance was provided using a gas mixture of $40 \%$ oxygen, $60 \%$ nitrous oxide and 1.5 - $2 \%$ sevoflurane. During endotracheal intubation, systolic arterial blood pressure (SAP), diastolic arterial blood pressure (DAP) and heart rates (HR) were recorded before anesthesia induction, at laryngoscopy, and after intubation at $1 \mathrm{st}, 3 \mathrm{rd}, 5$ th, and 10th minutes.

After surgery, when the TOF ratio was $3 / 4$, the inhalation agent was stopped and the patient was ventilated using $100 \%$ $\mathrm{O}_{2}$ manually. To prevent the hemodynamic reactions to extubation, the drugs used before anesthesia induction were administered with the same doses before extubation, and then 2 minutes the patients were extubated. In the extubation period the SAP, DAP and HR values of the patients were recorded before extubation and at 1st, 3rd, 5th, and 10th, minutes after extubation.

The data were presented as mean \pm standard deviation where appropriate. First, Kolmogorov-Smirnov test was used to determine if the values showed normal distribution. The values with normal distribution (BP, HR, weight and height) were analyzed using ANOVA and Dunnett test was used for post hoc comparison. Nonparametric data were analyzed using Chi square test. $\mathrm{P} \leq 0.05$ was regarded as statistically significant.

\section{Results}

There were no significant differences among the groups regarding patient demographics and ASA classes (Table 1).

The heart rates values of the study groups both after in- 


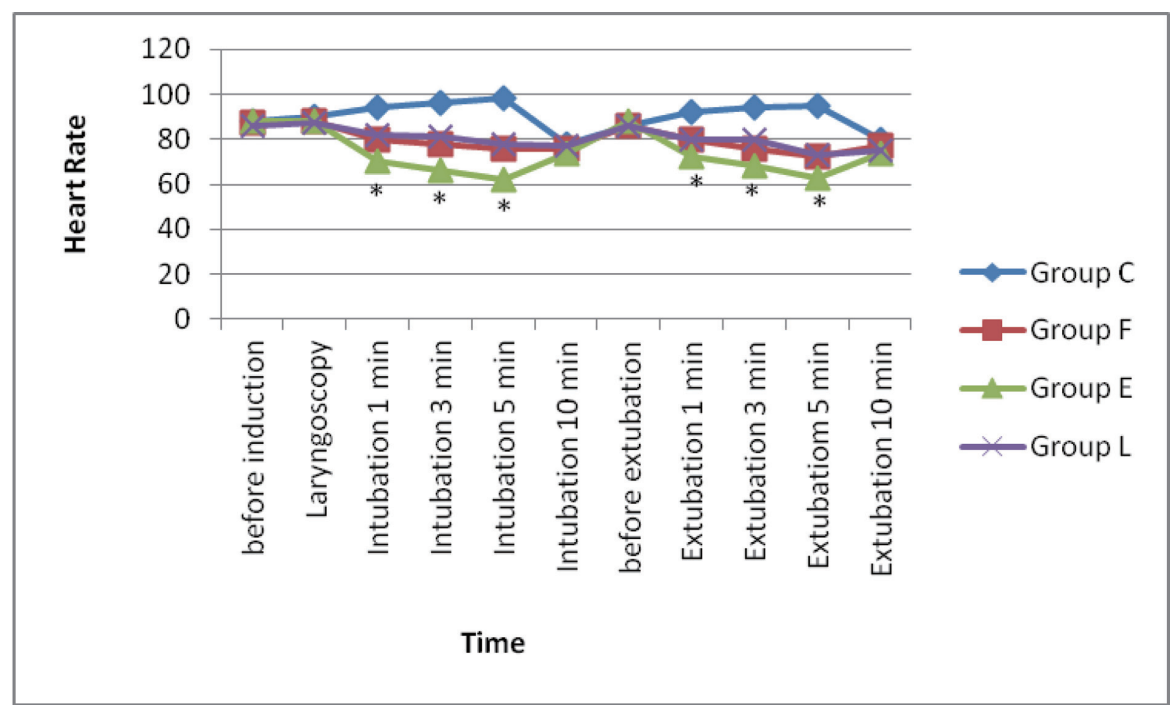

Figure 1. Heart rates of the groups, $\left({ }^{*} \mathrm{P}<0.05\right)$.

tubation and extubation were lower than those in the control group $(\mathrm{P}<0.01)$. When the three study groups were compared in respect of heart rates changes the values in the esmolol group after intubation and extubation at 1st, 3 th, and 5 th minutes were significantly lower in esmolol group when compared to fentanyl and lidocaine groups $(\mathrm{P}<0.05)$. In all other measurement times, there was no any different of heart rates among the three groups (Fig. 1).

The systolic and diastolic arterial blood pressures values of the study groups both after intubation and extubation were lower than those in the control group $(\mathrm{P}<0.01)$. The systolic and diastolic arterial blood pressures values after intubation and extubation at $1 \mathrm{st}, 3$ th, and 5 th minutes were significantly lower in esmolol group when compared to fentanyl and lidocaine groups $(\mathrm{P}<0.05)$. In all other measurement times, there was no any different of arterial blood pressures among the three groups (Fig. 2A, 2B).
When all groups were compared at the aspect of the side effects or complications developed in the intubation and extubation period, no significant difference among the groups was determined.

\section{Discussion}

We aimed to compare a beta blocker like esmolol, an opioid like fentanyl and a local anesthetic like lidocaine regarding their use during laryngoscopy, intubation and extubation to provide a smooth intubation and extubation and a safe postanesthetic care period. This study showed that $1 \mathrm{mg} \mathrm{kg}^{-1}$ of esmolol and lidocaine, and $1 \mu \mathrm{g} \mathrm{kg}^{-1}$ of fentanyl administered before both induction and emergency of anesthesia decrease the hemodynamic responses to laryngoscopy, intubation and extubation. Esmolol is more effective to prevent this hemo-
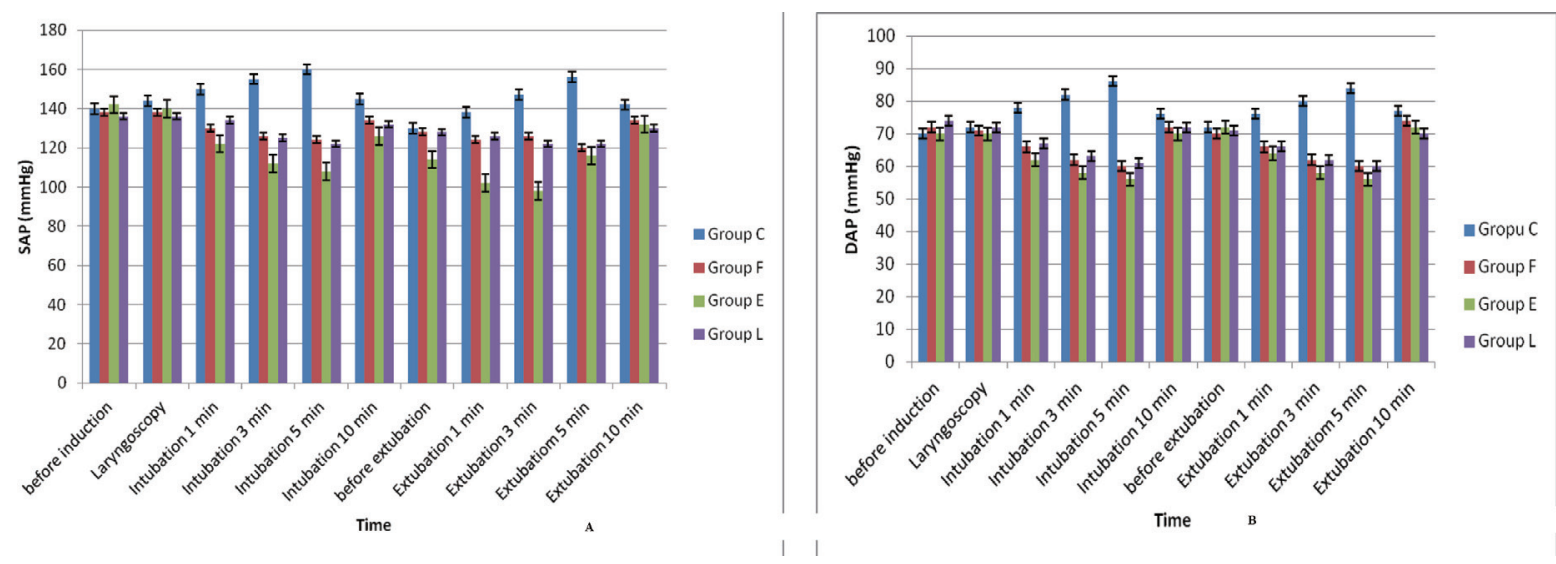

Figure 2. A: SAP values of the groups, ${ }^{*} P<0.05$; $B$ : DAP values of the groups, ${ }^{*} P<0.05$. 
dynamic responses when compared fentanyl and lidocaine.

It is thought that fentanyl suppresses the hemodynamic response by increasing the depth of anesthesia and decreasing the sympathetic discharge [8]. Kautto et al. [9] found that $2 \mu \mathrm{g} \mathrm{kg}_{-1}$ of fentanyl administration 3.5 minutes before laryngoscopy and endotracheal intubation only decreased the heart rate but $6 \mu \mathrm{g} \mathrm{kg}_{-1}$ fentanyl decreased both the heart rate and the blood pressure. There is little data in the literature about the use of fentanyl to prevent the increase in heart rate and blood pressure during extubation. In a randomized, double-blind study to examine the effects of intravenous fentanyl ( 1 to $2 \mu \mathrm{g} \mathrm{kg}_{-1}$ ) on hemodynamic changes during tracheal extubation and emergence from anesthesia in 60 ASA physical status I or II patients undergoing elective gynecological surgery. In the study Nishina and collegues [10] reported that a bolus dose of intravenous fentanyl $2 \mu \mathrm{g} \mathrm{kg}_{-1}$ given at the time of peritoneal closure was of value in attenuating the cardiovascular changes associated with tracheal extubation and emergence from anesthesia, and that this treatment did not prolong the recovery. In our study the administration of fentanyl $1 \mu \mathrm{g} \mathrm{kg}_{-1}$ both before intubation and extubation depressed the increase in heart rate and systolic arterial blood pressures when compared the control group. We did not observe any complications or prolongation of the recovery in those patients.

Esmolol has been used in general anesthesia for hemodynamic stability at intubation and during surgical period. Furthermore, esmolol has been used to prevent the HR and BP increase due to airway irritation during extubation. Parnass and collegues [11] used 100 and $200 \mathrm{mg}$ esmolol and found that both doses were enough to suppress HR and BP when compared to the controls, and they did not found any difference between the treatment groups. Korpinen and collegues[12] reported that the administration of esmolol $2 \mathrm{mg}$ $\mathrm{kg}^{-1}$ IV 2 minutes before laryngoscopy and intubation suppressed the increase in heart rates but not in arterial blood pressures.

Keskin and collegues [13] administered esmolol $500 \mu \mathrm{g}$ $\mathrm{kg}^{-1}$ IV bolus before extubation and infused $200 \mu \mathrm{g} \mathrm{kg}^{-1}$ esmolol in 4 minutes after extubation and they concluded that it was effective in controlling the BP and HR during extubation. Ersin and collegues [14] reported that IV Esmolol dose of $1.5 \mathrm{mg} \mathrm{kg}^{-1}$ was effective in preventing the hemodynamic response when administered 3 minutes before extubation. In other studies esmololol is found to decrease the DAP less than SAP and this resulted in a better control of the systemic blood pressure and HR $[15,16]$. In our study, administration of $1 \mathrm{mg} \mathrm{kg}^{-1}$ of esmolol both before intubation and extubation suppressed the increase in heart rates and arterial blood pressures following intubation or extubation when compared the control group. In addition, we observed that the $\mathrm{HR}$ and BP values of the esmolol group were significantly lower compared to the lidocaine and fentanyl group.

Lidocaine has used for hemodynamic stability during general anesthesia. At serum concentrations higher than 5 $\mathrm{mg} \mathrm{mL}^{-1}$, lidocaine causes suppression of cardiovascular system, central nervous system and cough reflex [14]. Basagan and collegues [6] compared lidocaine, diltiazem and verapamil regarding their effectiveness in prevention of the hemodynamic response to intubation and used lidocaine in a dose of $1 \mathrm{mg} \mathrm{kg}^{-1}$ in their study. They recorded the increases in MAP and DAP values during and 2 minutes after intubation. They found that the increase in SAP, DAP and MAP values 1 minute after intubation were less than the controls. Kelsaka and collegues [5] investigated the effects of lidocaine, magnesium and fentanyl on the hemodynamical response to laryngoscopy and intubation. They reported that the SAP, DAP and MAP values returned to preintubation levels just 1 minute after intubation and were even lower at postintubation $3 \mathrm{rd}$ and 5 th minutes when compared to the controls. Mikawa and colleagues [17] investigated the suppressive effect of lidocaine on cough reflex and compared lidocaine and verapamil. They found that lidocaine infusion during extubation suppressed hypertension and tachycardia but was insufficient to suppress the increase in plasma catecholamine concentrations. Similarly, we observed that lidocaine $1 \mathrm{mg} \mathrm{kg}^{-1}$ administered in our study before intubation and extubation suppressed the increase in HR and BP when compared the control group. But lidocaine did not effective to prevent the hemodynamic responses when compared esmolol as well as.

Relatively few investigations have been conducted to compare esmolol, fentanyl and lidocaine to prevent the hemodynamic responses to laryngoscopy and intubation, but there is not nay comparison of the drugs for extubation. Helfman and colleagues [18] compared single bolus of esmolol, fentanyl and lidocaine in blunting the hemodynamic responses to laryngoscopy and intubation in noncardiac surgery. They reported that only esmolol provided consistent and reliable protection against increases in both heart rate and systolic blood pressure accompanying laryngoscopy and intubation. In another study, Feng and colleagues [19] compared fentanyl $3 \mu \mathrm{g} / \mathrm{kg}$, esmolol $2 \mathrm{mg} / \mathrm{kg}$ and lidocaine $2 \mathrm{mg} / \mathrm{kg}$ for attenuation of cardiovascular response to laryngoscopy and tracheal intubation in noncardiac surgery. Their results of that study showed that only esmolol could reliably offer protection against the increase in both HR and SAP. Ugur and colleagues [20] compared the three drugs in doses of $1.5 \mathrm{mg} / \mathrm{kg}$ of esmolol and lidocaine, and $1 \mu \mathrm{g} / \mathrm{kg}$ of fentanyl for prevention of tachycardia and hypertension caused by endotracheal intubation. They concluded that administration of esmolol $1.5 \mathrm{mg} / \mathrm{kg} 2$ minutes before intubation prevents tachycardia and an increase in blood pressures caused by laryngoscopy and tracheal intubation. In our study we firstly compared $1 \mathrm{mg} / \mathrm{kg}$ of esmolol, $1 \mu \mathrm{g} / \mathrm{kg}$ of fentanyl and $1 \mathrm{mg} / \mathrm{kg}$ of lidocaine for the hemodynamic control both intubation and extubation periods.

In conclusion, when administered before induction and 
emergency of anesthesia $1 \mathrm{mg} \mathrm{kg}_{-1}$ of esmolol and lidocaine, and $1 \mu \mathrm{g} / \mathrm{kg}$ of fentanyl are effective in suppressing the hemodynamic response to laryngoscopy, intubation and extubation without complication. Esmolol may be more effective to prevent those responses comparing fentanyl and lidocaine. Furthermore studies regarding the dose of those drugs should be required.

\section{Grant Support}

None sources of financial support for the work.

\section{References}

1. Hamaya Y, Dohi S. Differences in cardiovascular response to airway stimulation at different sites and blockade of the responses by lidocaine. Anesthesiology. 2000;93(1):95-103.

2. Edwards ND, Alford AM, Dobson PM, Peacock JE, Reilly CS. Myocardial ischaemia during tracheal intubation and extubation. Br J Anaesth. 1994;73(4):537-539.

3. Forbes AM, Dally FG. Acute hypertension during induction of anaesthesia and endotracheal intubation in normotensive man. Br J Anaesth. 1970;42(7):618-624.

4. Kurian SM, Evans R, Fernandes NO, Sherry KM. The effect of an infusion of esmolol on the incidence of myocardial ischaemia during tracheal extubation following coronary artery surgery. Anaesthesia. 2001;56(12):1163-1168.

5. Kelsaka E, Barış S, Karakaya D, at al. Preventing Homodynamic Response to Laryngoscopy and Tracheal Intubation; Comparison of The Effects of Lidocaine, Magnesium And Fentanyl. JTAICS 2002; 30: 369-375.

6. Başağan Moğol E, Bilgin H, Korfalı G, Osma S. Comparing the Effects of Lidocaine, Diltiazem and Verapamil for the Control of Hemodynamic Responses During Intubation. JTAICS 2000; 28: 393-398.

7. Bidwai AV, Bidwai VA, Rogers CR, Stanley TH. Bloodpressure and pulse-rate responses to endotracheal extubation with and without prior injection of lidocaine. Anesthesiology. 1979;51(2):171-173.

8. Shafer SL, Varvel JR. Pharmacokinetics, pharmacodynamics, and rational opioid selection. Anesthesiology. 1991;74(1):53-63.

9. Kautto UM. Attenuation of the circulatory response to laryngoscopy and intubation by fentanyl. Acta Anaesthesiol Scand. 1982;26(3):217-221.

10. Nishina K, Mikawa K, Maekawa N, Obara H. Fentanyl attenuates cardiovascular responses to tracheal extubation. Acta Anaesthesiol Scand. 1995;39(1):85-89.

11. Parnass SM, Rothenberg DM, Kerchberger JP, Ivankovich AD. A single bolus dose of esmolol in the prevention of intubation-induced tachycardia and hypertension in an ambulatory surgery unit. J Clin Anesth. 1990;2(4):232237.

12. Korpinen R, Simola M, Saarnivaara L. Effect of esmolol on the hemodynamic and electrocardiographic changes during laryngomicroscopy under propofol-alfentanil anesthesia. Acta Anaesthesiol Belg. 1998;49(2):123-132.

13. Keskin H. Emrah, Bilgin Hülya. Comparing the Effects of Lidocaine and Esmolol for the Control of Hemodynamic Responses During Laryngoscopy, Intubation and Extubation. JTAICS 2005; 33: 463-470.

14. Ersin Y, Çelik M, Besler M, Devrim S, Kaşıkçı T. Comparing the effects of esmolol and diltizem to depressing the haemodynamic response against tracheal extubation. The Medical Journal of SSK Göztepe Educational Hospital. 2005; 20(4):193-196.

15. Turlapaty P, Laddu A, Murty VS, et al. Esmolol: a titratable short-acting inravenous beta blocker for acute critial care settings. Am Heart J 1997; 114: 866-885.

16. Sear JW. Recent advances and developments in the clinical use of i.v. opioids during the peroperative period. $\mathrm{Br}$ J Anaesth. 1998;81(1):38-50.

17. Mikawa K, Nishina K, Takao Y, Shiga M, Maekawa N, Obara H. Attenuation of cardiovascular responses to tracheal extubation: comparison of verapamil, lidocaine, and verapamil-lidocaine combination. Anesth Analg. 1997;85(5):1005-1010.

18. Helfman SM, Gold MI, DeLisser EA, Herrington CA. Which drug prevents tachycardia and hypertension associated with tracheal intubation: lidocaine, fentanyl, or esmolol? Anesth Analg. 1991;72(4):482-486.

19. Feng CK, Chan KH, Liu KN, Or CH, Lee TY. A comparison of lidocaine, fentanyl, and esmolol for attenuation of cardiovascular response to laryngoscopy and tracheal intubation. Acta Anaesthesiol Sin. 1996;34(2):61-67.

20. Ugur B, Ogurlu M, Gezer E, Nuri Aydin O, Gursoy F. Effects of esmolol, lidocaine and fentanyl on haemodynamic responses to endotracheal intubation: a comparative study. Clin Drug Investig. 2007;27(4):269-277. 